\title{
RIGIDITY AND CONTINGENCY
}

\author{
RIGIDEZ Y CONTINGENCIA
}

Eduardo García Ramírez

\begin{abstract}
At least since Kripke (1980) it has been generally accepted that true identity statements involving proper names are necessarily true. This view is allegedly supported by our most ordinary, pretheoretic intuitions according to which ordinary proper names are rigid designators. This paper challenges the established status of this view. Section 1 develops the context of the debate by presenting the intuitions of rigidity and of contingency of identity found among competent speakers. Section 2 shows how the latter constitute a serious problem for the received view, one that cannot be easily ignored. Section 3 considers three available proposals intended to solve the problem and shows why they fail. Section 4 briefly describes a way to make compatible the intuitions of rigidity and of contingency, a consequence of which is the acceptance of the possibility of contingently true identity statements. If this is correct, then a longstanding thesis of contemporary orthodoxy owed to Kripke (1980), namely, that the rigidity of names entails the necessity of true claims involving them, turns out to be doubtful. Section 5 considers some philosophical consequences of accepting such a view.
\end{abstract}

KEYWORDS: Proper names, identity statements, speaker intuitions.

\section{RESUMEN}

Al menos desde Kripke (1980) se ha aceptado de manera general que toda oración de identidad verdadera que emplee nombres propios es necesariamente verdadera. Esta postura está supuestamente apoyada por intuiciones ordinarias, preteóricas, según las cuales los nombres propios ordinarios son designadores rígidos. Este texto pretende cuestionar el estatus establecido de esta postura. La primera sección desarrolla el contexto del debate al presenter las intuiciones de rigidez y de contingencia de la identidad que es possible encontrar entre hablantes competentes. La segunda sección muestra cómo es que estas últimas constituyen un problema serio para la postura tradicional, un problema que no puede ser fácilmente ignorado. La tercera sección considera tres propuestas disponibles que pretenden resolver el problema y muestra cómo éstas fracasan. La cuarta sección describe brevemente una manera en la que es possible hacer compatibles las intuiciones de rigidez y contingencia, con la consecuencia de aceptar 
la posibilidad de que existan oraciones de identidad contingentemente verdaderas. Si esto es correcto, entonces una de las tesis más duraderas de la ortodoxia contemporánea debida a Kripke (1980), a saber, que la rigidez de los nombres implica la necesidad de las afirmaciones verdaderas que los emplean, resulta ser dudosa. La última sección considera algunas consecuencias filosóficas de aceptar esta propuesta.

PALABRAS CLAVE: Nombres propios, oraciones de identidad, intuiciones de hablantes.

\section{IntUitions of Rigidity AND CONTINGENCY}

Competent speakers commonly use ordinary proper names to refer to some individual person, location, or object in the course of making a modal claim about that person, location or object. The way such expressions are used to make modal claims, and what this use says about the nature of such expressions, has been the subject of much discussion, particularly when it comes to accounting for the intuitions that competent speakers have about the truth conditions of the associated statements. It is these intuitions that constitute the relevant explananda. Let me then consider the explananda in detail.

\subsection{Intuitions of Rigidity}

According to Kripke (1980), if we want to properly understand rigidity we must look at competent speaker intuitions because "we have a direct intuition of the rigidity of names, exhibited in our understanding of the truth conditions of particular statements." [Kripke, 1980: 14] Thus, Kripke asks us to consider the truth conditions of the following two statements:

(1) Aristotle might not have been Aristotle.

(2) Aristotle might not have been the teacher of Alexander the Great.

Intuitively, Kripke claims, (1) seems to express something necessarily false, while (2) appears to express something true. If so, then, again intuitively, it seems that (1) and (2) differ in modal profile. Yet, (1) and (2) only differ in that (2) makes use of a definite description ('the teacher of Alexander the Great') whereas (1) uses an ordinary proper name ('Aristotle'). Thus, according to these intuitions the proper name 'Aristotle' and the definite description 'the teacher of Alexander the Great' differ in their respective modal profile.

Now consider the modal truth conditions of statement (3)

(3) Aristotle was fond of dogs. 
Intuitively, again, it seems that all one needs to determine whether (3) expresses something true in any given world is to ask what is true about Aristotle himself in such world. ${ }^{1}$

Together these intuitions deliver the following explananda $\mathrm{E}_{1}-\mathrm{E}_{3}$ for any satisfactory account of our modal intuitions:

$\mathrm{E}_{1}$ : Statements (1) and (2) differ in truth conditions.

$\mathrm{E}_{2}$ : 'Aristotle' and 'the teacher of Alexander the Great' differ in modal profile.

$\mathrm{E}_{3}$ : The modal truth conditions of (3) depend only on Aristotle.

Kripke's (1980) account of modal intuitions $E_{1}-E_{3}$ is based on the semantic notions of rigid designator and rule of rigidity, which are defined as follows.

- Rigid Designator: A designating term is a rigid designator "if in every possible world it designates the same object." [1980:48 $]^{2}$

- Rule of Rigidity: "that there is a single individual and a single property such that, with respect to every counterfactual situation, the truth conditions of the proposition are the possession of the property by that individual in that situation.” [1980:10]

Given the assumption that the truth of statements (1)-(3) depends on what properties the designated objects have, these semantic notions entail that statements involving rigid designators will have truth conditions that observe the rule of rigidity. To properly account for the explananda, the semantic account makes two bold empirical claims about ordinary proper names and definite descriptions. ${ }^{3}$

1 These examples and intuitions reflect what are traditionally taken to be Kripke's evidence on behalf of his theory. For details see Hughes 2004, Gómez-Torrente 2006, Salmon 1982 and 2003, Soames 2002, and Stanley 1997, among others.

2 It is often argued that we must distinguish between different versions of rigid designator (see Kaplan, 1989; Salmon, 1981, 2003, 2005; Soames, 2002; and Gómez-Torrente, 2006), varying with respect to what happens in worlds where the referent of the designator does not exist. The differences between these versions of rigid designator are irrelevant for the purpose of the present discussion.

${ }^{3}$ Kripke (1980) makes a further distinction between de jure and de facto rigid designators. A designator is de jure rigid, if its reference "is stipulated to be a single object, whether we are speaking of the actual world or a counterfactual situation". There is de facto rigidity when "a description 'the $\mathrm{x}$ such that $\mathrm{Fx}$ ' happens to use a predicate ' $\mathrm{F}$ ' that in each possible world is true of one and the same unique object (e.g., 'the smallest prime' rigidly designates the number two)." [Kripke, 1980: 21, ft 21] According to Kripke, ordinary proper names are de jure rigid, while some definite descriptions may be so only de facto. 
- Proper Names: Ordinary proper names (i.e., names of persons, locations, cities, etc.) are rigid designators.

- Definite Descriptions: Ordinary definite descriptions (i.e., of persons, locations, cities, etc.) are non-rigid designators.

Together, the semantic definitions and the empirical claims offer an account of $\mathrm{E}_{1}-\mathrm{E}_{3}$.

It is not hard to see how this account, and its accompanying intuitions of rigidity, give place to the received view according to which identity is necessary. If as Kripke (1980) claims, ordinary proper names are rigid designators, then they denote one and the same individual in all possible worlds. If we apply this to the case of identity statements involving only proper names, it follows that all true such statements are necessarily true. To see this, one need only observe that if an identity statement is true, then the designating terms involved denote the same object 0 . Now, if these terms happen to be rigid designators, then each will denote $o$ in every possible world. It follows that there is no world at which these designators will denote different objects and, hence, no possible world at which the statement is false. Thus, true identity statements involving only proper names are necessarily true.

\subsection{Intuitions of Contingency}

According to Kripke, competent speakers' modal intuitions are "very heavy evidence", it is hard to know "what more conclusive evidence one can have about anything, ultimately speaking." [Kripke, 1980:42]. As it happens, competent speakers do not only have intuitions of rigidity, as Kripke calls them, they also happen to have the intuition that there are contingently true identity statements involving only proper names.

The intuition that there are contingently true identity statements is usually considered a recalcitrant one. Yet, evidence that such intuition exists comes from considering a variety of cases. These cases are concerned with both, pairs that happen to be identical but could have been distinct (i.e., contingent identity), and pairs that happen to be distinct but could have been identical (i.e., contingent nonidentity). Some cases involve material constitution as part of the relation between the identity (non-identity) pair, others do not. Because of space limitations I will only present four cases owed to Gibbard (1975), Lewis (1986), and Karmo (1983), but there are plenty more (see Noonan, 1991, and 1993; Perry, 1972; Myro, 1986a and 1986b; for a general survey see Gallois, 1998; and Schwartz, 2013). 
Gibbard's [1975:191] example is perhaps the most well known case of contingent identity. Gibbard presents us with a case of contingent identity related to material constitution. Consider, for example, the process of creating a statue of, say, Goliath by using a certain lump of clay. A common procedure to achieve this goal would be to create, first, two different pieces each one corresponding to the upper and lower parts of Goliath. With both pieces completed, the second step involves sticking them together, in order to form a single object made out of clay. As a result we obtain a new object, namely, a new lump of clay that constitutes the statue of Goliath. This clay statue of Goliath came into existence only after the second step of the procedure had taken place. Before that there was no statue. Now, the lump of clay that now constitutes the statue came into existence at the same point in time as the statue, namely, only after the second step takes place. Before that there were only two smaller and distinct lumps of clay. It seems, thus, that by creating the complete statue we have created the lump of clay.

Now suppose that for some reason you dislike the statue and decide to destroy it by smashing it out of existence. As a result of this third step the statue was sent out of existence. After that there is no statue. Similarly, since it has been obliterated, the lump of clay that used to constitute the statue is also sent out of existence. After the third step there is no lump of clay. Hence, it seems that by destroying the statue we have also destroyed the lump of clay.

Gibbard asks us to consider this intuitive scenario to reflect upon a few substantial lessons concerning material constitution. Whenever we have a statue materially constituted by a certain chunk of matter, we seem to have a pair of objects that share important metaphysical features. They both come into and out of existence at the same point in time and, thus, they persist through time with exactly the same conditions. Furthermore, both the lump and the statue have each and every one of their properties in common. "They began at the same time, and on any usual account, they had the same shape, location, color, and so forth at each instant in their history; everything that happened to one happened to the other; and the act that destroyed the one destroyed the other." [Gibbard, 1975:191]

Thus, the lump-statue pair satisfies Leibniz's principle of identity of indiscernibles according to which if every property of $x$ is a property of $y$, and vice versa, then $x$ and $y$ are identical. Hence, it seems best to consider the lump-statue pair as constituting a single object or, if you prefer, a pair of objects that constitute an identity pair. We can express this intuitive truth by means of an identity statement. Furthermore, we can do so by using proper names. Following Gibbard (1975) we can coin a couple new names for this purpose. Let us call the statue 'Goliath' and 
the piece of clay 'Lumpl'. Given the above, the following identity statement is intuitively true:

(4) Lumpl is identical with Goliath.

Thus far, we have an intuitively true identity statement involving proper names. But speakers' intuitions appear to go further, showing that (4) is not only intuitively true but also contingently so. To see this one need only observe that just as easily as Lumpl is shaped in the form of Goliath, thereby becoming the statue named 'Goliath', it could have been shaped in any other distinct form, thereby becoming something else, distinct from Goliath. In such a case Lumpl would exist but Goliath would not. Suppose, for example, that we follow steps one and two of the above described process for creating Goliath the statue. We stick together both smaller lumps of clay corresponding to the lower and upper parts of Goliath, turning it into a single bigger lump (i.e., Lumpl) and ipso facto creating Goliath. But now suppose we dislike the result for whatever reason and so decide not to let the clay dry and squeeze it into a ball. In so doing Lumpl would have changed its shape, yet it would still exist. Goliath, however, would exist no longer as there is now a ball in place of the statue we originally named 'Goliath'. At this point "Lumplwould not be Goliath, even though they both existed." [Gibbard, 1975:191]

It follows from this that, with respect to statement (4), intuitions tell us that it is contingently true. In other words, Lumpl is identical with Goliath yet not necessarily so, as Lumpl may have been a ball of clay in which case Goliath would not have existed. Statement (4) is, intuitively, true yet only contingently so. Given that (4) involves only the use of proper names, this result is seriously problematic for the received view (see Kripke, 1980) according to which ordinary proper names are rigid designators and identity statements involving only proper names are necessarily true if true at all, or so I will argue in section 2 .

One may worry that the fact that the clay materially constitutes the statue may be a source of confusion in this case; as it may be argued that material constitution does not constitute identity (but see below). Let us then consider a different case, this time material constitution is not involved, and yet intuitions tell us that we have contingently true identity statements.

Lewis [1986:248] asks us to consider the historical case of the Great Western Railway (GWR), a British Railway created in 1838 and which still operates nowadays. The goal of the GWR was to connect London with the southwest and west of England. To do so the GWR should have had absorbed two other railways, the one running from Bristol to Gloucester and the other from Gloucester to Birmingham. 
Negotiations failed by 1845 and the whole line going from Bristol to Birmingham via Gloucester fell into rival hands. Had negotiations gone differently, the GWR would have had as a proper part a railway line that it now lacks. It would have been a greater railway. What is nowadays known as the Great Western Railway is only a part of what it was meant to be, however, it turned out to be the whole of it.

There seem to be two different railways being referred to by 'GWR'. On the one hand, there is the GWR as it should have been had things evolved as initially planned. Such railway includes both, what we now know as the Great Western Railway as well as the Bristol-Gloucester-Birmingham railway. On the other hand, there is the GWR as it in fact turned out to be, given that things went awry. This railway includes only a part of the Great Western Railway as it should have been, without the Bristol-Gloucester-Birmingham railway. To avoid confusions we may use different names for each one of these two different railways. Let 'GWR+' name the Great Western Railway as it should have been, the bigger railway that includes the Bristol-Gloucester-Birmingham line. Let 'GWR-' name the railway as it turned out to be, without the Bristol-Gloucester-Birmingham line. Finally, let us also use the name 'GWR' as it is ordinarily used nowadays, to refer to the still operating Great Western Railway.

With these names in hand we can describe the historical situation as follows. There is a railway, the Great Western Railway or GWR, as it is commonly known. It is uncontroversial that the Great Western Railway is identical with the shorter railway, namely the GWR-. Thus, statements (5) and (6) turn out to be both true.

(5) The GWR is identical with the GWR-.

(6) The GWR is not identical with the GWR+.

This, however, is the result of an unfortunate series of events. Had things gone as planned, the GWR would have included the Bristol-GloucesterBirmingham railway. In other words, had things gone as planned, the GWR would have been identical with the bigger railway, namely, the GWR + . Intuitively there is no metaphysical or conceptual necessity precluding this from happening. Even though it didn't, the GWR could have very easily (and almost did) absorbed the Bristol-Gloucester-Birmingham railway. Thus, intuitively, $\left(5^{*}\right)$ also turns out to be true, as it expresses a genuine nearby possibility.

$\left(5^{*}\right)$ The GWR could have been identical with the GWR+.

Now, in the counterfactual scenario described by $\left(5^{*}\right)$ it is also the case that the GWR is not identical with the minor railway, namely, GWR- for the latter lacks 
a part that the GWR includes in such scenario. Thus, intuitively, (6*) also turns out to be true if $\left(5^{+}\right)$is.

(6*) The GWR could have been not identical with the GWR-.

Briefly put, the peculiar historical situation of the Great Western Railway can be summarized in four distinct statements, all of which are intuitively true.:

(5) The GWR is identical with the GWR-.

(6) The GWR is not identical with the GWR+.

(5*) The GWR could have been identical with the GWR+.

(6*) The GWR could have been not identical with the GWR-.

Yet, the only way for all these four statements to be true is for statements (5) and (6) to be true yet only contingently so. Thus, we can say that, with respect to (5) and (6), speaker intuitions tell us that they both are contingently true. This result shows that not only are there intuitions of contingent identity, but also of contingent non-identity — i.e., pairs of actually distinct objects that might have, nonetheless, been the same (e.g., GWR and GWR+).

Both statements, (5) and (6), are true identity statements involving only names and, thus, they should not turn out to be contingently true according to Kripke (1981). As I will show in section 2, just like contingent identity, contingent nonidentity is inconsistent with the semantic account (see 1.1 above), and examples of contingent non-identity are bountiful. Karmo (1983) offers three of which I would like to consider two, none of which involve material constitution.

Consider first the case of family clans (Karmo, 1985:185-186). Whenever two clans intermarry they become a single clan as a result, that is, as a matter of anthropological fact, the very nature of family clans. This anthropological datum already shows how there can be contingent non-identity, as it is part of the metaphysics (so to speak) of family clans that they may fuse into a single one. So consider the case of two different clans, the MacLarens an the Adairs. For generations they have inhabited neighboring portions of land, without ever intermarrying. Surprised at this peculiar fact, an anthropologist may want to say that, even though they are distinct clans, the MacLarens and the Adairs could have very easily become a single clan, they could have been the same clan. Thus, intuitively, statement (7) is true.

(7) MacLaren and Adair are not the same clan, but could have been.

Clan names are ordinary names, yet we can use them to express true identity statements, like (7), according to which the identity itself is contingent. Statues, 
clans, and railways are not the only kind of entity that seem to justify contingent identity claims. The same seems to hold for persons. Karmo (1985:185-186) asks us to consider the case of identical twins. As a matter of fact they result from the splitting of a fertilized ovum at an early stage of pregnancy. This phenomenon is, even today, a rather obscure one in need of explanation. It is, in fact, unpredictable as a fertilized ovum is more likely not to split and continue its development as a single embryo. Consider two identical twins in particular, Linda and Lisa. Given how things turned out to be, they happen to be two distinct individuals. Yet, had the most likely outcome transpired, the ovum from which they stem would not have split at an early stage of pregnancy, and Linda and Lisa would not have existed as two separate individuals. There would have been a single one with exactly the same DNA as them. Thuis, intuitively, (8) is true.

(8) Linda and Lisa are not the same person, but could have been.

Together, these four cases of contingent identity and non-identity strongly suggest there is one more intuition to account for when it comes to explaining ordinary proper names, $\mathrm{E}_{4}$.

$\mathrm{E}_{4}$ : Identity statements (4) to (8) express contingently true identity propositions.

\section{The Problem of Contingent Identity And Non-Identity}

Kripke's (1980) account of $\mathrm{E}_{1}-\mathrm{E}_{3}$ has become orthodoxy, with most (if not all) analytic philosophers endorsing it. Even those that wish to offer alternative accounts of the semantics for proper names appear to be convinced of Kripke's claim that rigidity is a semantic, and thus not an optional, feature of ordinary proper names. Stanley (1997), for example, defends a descriptivist account of the meaning of proper names, but still talks about "the fact that natural-language proper names are rigid designators" and takes it to be "an empirical discovery about natural language." [Stanley, 1997:555] If it is a fact of proper names that they are rigid designators, then, one would think, it should not be possible to find ordinary referential uses of proper names where no rigidity is involved. Yet, that is precisely what happens in statements (4) to (8).

Philosophers of language in general are so convinced of the semantic claim for rigidity that Kripke's theory is even seen as some kind of obvious truth. Stalnaker (1997), for example, goes as far as claiming that "the positive case for the theses that Kripke defends is not novel philosophical insight and argument, but naïve common sense." [Stalnaker, 1997:537] It seems fair to say that the view 
is accepted almost without questioning. Evidence of this is offered by the fact that accounting for the semantic rigidity of proper names has become one of the basic desiderata for any acceptable theory of proper names.

Yet, this widespread agreement has not precluded philosophers from noticing that the theory has problems with contingent identity (see Gibbard, 1975; Lewis, 1986; Gallois, 1986 and 1998; and Stalnaker, 1997). Some have tried to offer an account that fits Kripke's model. Yet, a satisfactory account of the intuition of contingency compatible with Kripke's views is still in the wanting.

Unfortunately for the orthodoxy, the contingency intuition is not easily ignored and poses an important threat to the received view. Kripke's widely accepted view excludes the possibility of contingent identity. If an identity statement involves proper names, then each name refers rigidly to whichever referent it has. In other words, each name refers to one and the same object across possible worlds. If, furthermore, such a statement happens to be true, then both names refer to one and the same object, and they do so rigidly, across all possible worlds that is. Hence, any such statement will be true in the actual world and across all possible worlds. If ordinary proper names are rigid designators, then any true identity statement involving ordinary proper names will be necessarily true. Briefly put, true identity statements involving proper names can only be contingently true if those names are not rigid designators.

It is tempting to say, given how well established the theory is among philosophers, that there is no such thing as contingent identity, and the associate intuitions are simply misleading. However, this strategy seems to be foreclosed to anyone following Kripke (1980) and his account of proper names. Kripke's theory is built on the assumption that competent speakers "have a direct intuition of the rigidity of names, exhibited in [their] understanding of the truth conditions of particular statements". [Kripke, 1980:14] And competent speakers happen to have the intuition that there are contingently true identity statements involving only proper names. The theory falsely predicts that there should be no such intuitions. We cannot simply dismiss the evidence of contingent identity, something needs to be fixed.

To further demonstrate that this is a substantial problem that cannot be easily avoided, let me consider three simple denial strategies one might be tempted to follow and show why they fail.

\subsection{Denying Identity}

The first reply denies that the so-called "cases of contingent identity" are genuine cases of identity (see Johnston, 1992). According to this strategy, the 
adequate relation that holds between, say, Lumpl and Goliath is that of material constitution, not the identity relation. If so, then (4) would be false and, hence, we should correct, rather than account for, intuition $\mathrm{E}_{4}$.

This strategy will not work for at least two reasons. First, because denying identity leads to deeper metaphysical trouble. As Yablo (1987) puts it, if Lumpl and Goliath are not identical then we must accept the "extraordinarily baffling metaphysical coincidence that [clay] and [statue], though entirely distinct, nevertheless manage to be exactly alike in almost every ordinary respect: size, weight, colour, shape, location, smell, taste, and so on indefinitely" [Yablo, 1987:295]. Things get more dubious once we notice that all parts of Goliath overlap with Lumpl. This is usually the case when Goliath is either a part of Lumpl or is identical with it. Since we reject identity, we must accept that Goliath is a part of Lumpl. And the same goes for Lumpl, since all of its parts overlap with Goliath. So we must conclude that Lumpl and Goliath are mutual parts, one is part of the other and vice versa (see Walters, 2017, for a recent take on these issues). Denying identity will only make things worse.

Second, and perhaps most importantly, denying identity simply does not eliminate the problem. Cases of material constitution are just a few among those of contingent identity. The Great Western Railway is not materially constituted by the Great Western Railway Minus. Had the human embryo not split, Linda and Lisa would have been a single person. It makes no sense to say that one would have materially constituted the other. If the railways and the persons of each example are not (or could not be) related by identity, how are they (or could they be) related?

\subsection{Denying Contingency}

The second reply denies that the relevant identities are in fact contingent. This is usually done by recalling Leibniz's Law according to which if $a$ and $b$ are identical then they share all properties. Suppose, the argument goes, that $a$ and $b$ are contingently identical. It seems obvious that $a$ has the property of being necessarily identical to $a$. If so then, by Leibniz's Law, $b$ also has this property. But then $\mathrm{a}$ and $\mathrm{b}$ cannot be contingently identical, since $b$ has the property of being necessarily identical to $a$.

There are several problems with this argument (see Lowe, 1982; Baldwin, 1984). The most obvious one is that its second premise is conflating two different claims (Kripke, 1971, does exactly this). First, there is the claim that any object is necessarily self-identical. Second, there is the claim that any object is necessarily 
identical to whatever it is identical to. The former claim seems obviously true, but it is also useless for denying contingency. The latter claim is just a denial of contingent identity and, hence, is not obviously true. To see this more clearly, consider both readings.

The second premise says that it is true of $a$ that it has the property of being necessarily identical to $a$. Under one reading the property that $a$ possesses is that of being necessarily self-identical. If so, then by Leibniz's Law, $b$ also has this property. It follows, then, that both $a$ and $b$ have the property of being necessarily selfidentical. It does not follow, however, that either one has the property of being necessarily identical to $a$. So it does not follow that $a$ and $b$ are, after all, necessarily identical.

Consider now the second alternative reading. On this reading the claim says that $a$ has, for some unexplained reason, the property of being necessarily identical to whatever it is identical to. If this is accepted then it does follow that $a$ has the property of being necessarily identical to $a$, and, by Leibniz's Law, it follows that $a$ and $b$ are necessarily identical. But this reading is question-begging. It assumes that identity relations are necessary when they hold. Contingent identity has no problem with Leibniz's Law. ${ }^{4}$

\subsection{Denying Namehood}

Finally, the third reply denies that the expressions used in statements of alleged contingent identity are genuine proper names. This is so because the terms involved in contingent identity statements have been recently introduced and lack any wide non-philosophical use. These names are more like abbreviations of the definite descriptions that were used to introduce them. On this view, if we want a descriptively introduced name to be a genuine proper name we must wait for it to be widely used outside the philosophy seminar, so that its meaning can settle into what it should be - i.e., one and the same referent across possible worlds.

There are at least two problems with this reply. First, it contradicts the view of proper names that Kripke (1980) expounds thanks to the semantic view. According to Kripke's (1980) causal theory of reference, all it takes for a referential expression ' $\mathrm{N}$ ' to be a genuine proper name is that it be given a referent

\footnotetext{
${ }^{4}$ There is also no problem with logically contingent identity de re. Under a logical interpretation of necessity a formula is necessary if and only if it is satisfied by every object in every model. If so, then the identity formula ' $x=y$ ' is not necessarily true, since it is not true of every pair of objects in every model. So logically contingent identity appears to be the rule, rather than the exception.
} 
0 , whether by perception or description, such that the use of ' $\mathrm{N}$ ' is appropriately causally linked with $o$. The names used in (4)-(8) all fit these criteria. It is, thus, not surprising to see Kripke (1980) consider recently introduced and non-widely used names to be genuine proper names.

Even if in some special cases [...] a referent is determined by a description, by some uniquely identifying property, what that property is doing $[\ldots]$ is fixing a reference. [...] The name denoting that object is then used to refer to that object, even in referring to counterfactual situations where the object doesn't have the properties in question. [Kripke, 1980:106-107]

Furthermore, Kripke (1980) repeatedly uses recent, descriptively-introduced, names with no wide non-philosophical usage to illustrate his claims about genuine proper names.

Let 'Descartes' be a name, or rigid designator, of a certain person, and let ' $B$ ' be a rigid designator of his body. Then if Descartes were indeed identical to $B$, the supposed identity, being an identity between two rigid designators, would be necessary, and Descartes could not exist without $B$ and $B$ could not exist without Descartes. [Kripke, 1980: 145]

Second, and perhaps most importantly, this reply should be avoided because it simply fails to stir the traditional view out of trouble. Suppose we accept that recent, descriptively-introduced, and purely philosophical names are not genuine names. We should then reject names such as 'Lumpl', and 'Goliath', for failing to be sufficiently settled and non-philosophical. But we still have cases of contingent identity that involve ordinary, widely used, non-philosophical proper names such as 'Great Western Railway' in (5) and (6).

I have considered three quick replies meant to deny that the traditional view has a problem with speaker intuitions of contingent identity (i.e., $\mathrm{E}_{4}$ ). Each reply fails for different reasons, but there is one inconvenience common to all, namely, that they imply that speaker intuitions concerning the truth conditions of modal statements are of little evidential value. If accepted, these replies constitute evidence against Kripke's main claim that "we have a direct intuition of the rigidity of names, exhibited in our understanding of the truth conditions of particular statements". [Kripke, 1980:14] Ultimately, denial strategies cast doubt over the very evidence that is used to support the semantic theory - i.e., speaker intuitions. For the sake of the received view it will be best to accept that $\mathrm{E}_{4}$ poses a real problem. 


\section{Problems with Available Accounts}

As I said above, Gibbard (1975), Lewis (1986), Gallois (1986), and Stalnaker (1997) have already noticed the threat posed by $\mathrm{E}_{4}$ and, thus, offer (or suggest) a way to fix the semantic theory. The literature includes only three alternative approaches, Gibbard's (1975) sortal rigidity; Lewis's (1986) quasi-rigidity also suggested by Stalnaker (1997); and Gallois's (1998) restricted rigidity. For reasons that I will present, none of them has gained supporters.

\subsection{Sortal Rigidity}

To account for $\mathrm{E}_{4}$ the semantic theory needs to gain in flexibility, so that the relevant names need not refer in all counterfactual scenarios to the very object they refer to in the actual one. In other words, proper names must stop behaving like rigid designators without thereby loosing their rigidity. To achieve this goal, Gibbard (1975) asks us to add one more level to the semantics of proper names by including reference to a sortal - e.g., statue or lump.

A proper name like 'Goliath' denotes a thing in the actual world, and invokes a sortal with certain persistence criteria. It then denotes the same thing-of-that-sort in every possible world in which it denotes at all. The name 'Goliath' itself, for instance, denotes a lump of clay and invokes the sortal statue; hence it denotes the same statue in every possible world in which that statue exists. [Gibbard, 1975:195]

In other words, according to Gibbard (1975) proper names are rigid but only according to a sortal. They refer to one and the same object in so far as this object belongs to the relevant sort of entity. Sortals are, in a way, like Fregean senses. Different coreferential names need not have exactly the same associated sortal. Whenever this is the case, those names may be coreferential in one world, if they happen to refer to the same object in that world through different sortals, and yet fail to be coreferential in another world, if they happen to refer to different objects in that other world through different sortals. Yet, each name is rigid relative to its sortal. Thus, we may have rigid names that corefer in some but not all worlds in virtue of being each associated to a distinct sortal. In all such cases there will be instances of contingent identity. If no such thing happens, if the relevant corefering names are associated with the same sortal, then given that they are rigid the relevant identity statement should hold across possible worlds, it should be necessarily true.

Sortal rigidity delivers enough flexibility, as it can easily account for the case of Lumpl and Goliath. 'Lumpl' and 'Goliath' invoke different sortals — i.e., lump and 
statue respectively — with different persistence criteria. 'Lumpl' rigidly denotes the same lump of clay and 'Goliath' the same statue, but given that they have different sortal-related persistence criteria, there may be worlds where one designates and the other does not. In such worlds, the identity does not hold. The account is clear and simple, but its explanatory power is fairly limited, as it can only account for cases of contingent identity where the elements of the identity pair belong to different sortals. According to sortal rigidity it is in virtue of the sortal difference, and associated persistence criteria, that the elements of the identity pair may fail to be identical. This is the case with (4), where the relevant names 'Lumpl' and 'Goliath' are each associated with distinct sortals (i.e., lump and statue).

(4) Lumpl is identical with Goliath.

But contingent identity goes well beyond these cases. Recall statement (5), a contingently true identity statement where the relevant names 'GWR' and 'GWR-' are both associated with exactly the same sortal (i.e., railway). Gibbard's (1975) sortal rigidity fails to account for (5), as it predicts that it should be necessarily true.

(5) The GWR is identical with the GWR-.

\subsection{Quasi-Rigidity}

In an attempt to account for cases of contingent identity statements Lewis (1986) claims that we should not "expect an ordinary proper name of a person or a thing — of a railway, say — to be strictly rigid." Instead, we should expect them to be quasi-rigid. A name is a quasi-rigid designator if it "name[s] at another world the counterpart there of what it names here". [Lewis, 1986:256] Quasi-rigidity relies on relations of comparative similarity among counterparts. Like comparative similarity, quasi-rigidity is inconstant. 'Aristotle' may quasi-rigidly refer to different individuals in different worlds, but also in the same world, depending on which counterpart relation is evoked by the use of the name.

Given that it does not rely on specific restrictions, such as sortal correspondence, but on flexible, context-dependent, relations of comparative similarity, quasirigidity is much more flexible and, hence, successful than Gibbard's sortal-rigidity. Quasi-rigidity directly accounts for $\mathrm{E}_{4}$. 'Lumpl' and 'Goliath' refer to different objects at different worlds because they evoke different counterpart relations. The same goes for 'GWR', which refers to different objects (i.e., different counterparts) in different worlds - i.e., GWR- in the actual world and the GWR+ in the world where the extra railway is absorbed. 
As I said, the inconstancy (i.e, context dependence) of counterpart relations gives the theory enough flexibility to account for all cases of contingent identity. Quasi-rigidity is so flexible that even one and the same "name is quasi-rigid under some counterpart relations but not under others" [Lewis, 1986:256].

Stalnaker (1997) observes that quasi-rigidity may also help reconcile Millian semantics with Leibniz's law. By Leibniz's Law if $a$ has some property that $b$ lacks, $a$ cannot be identical to $b$, but they can be counterparts. Thus, claims Stalnaker, "if "Shakespeare" is a quasi-rigid designator, relative to the actual world, "Shakespeare wrote plays" might be true in some other possible worlds — worlds in which a counterpart of Shakespeare wrote plays." [Stalnaker, 1997:553]

There are substantial costs associated with quasi-rigidity. Unfortunately, these costs seem to outweigh the benefits. First of all, endorsing quasi-rigidity is tantamount to rejecting the Millian view of the reference and rigidity of proper names that Kripke (1980) expounds (see Stalnaker, 1997). Counterfactual relations constitute reference relations for quasi-rigid terms. As such, one and the same quasi-rigid term may not only refer to different objects across possible worlds, it may even refer to multiple different ones within the same world, since - depending on the relevant context — one and the same individual may have multiple counterparts within a single world. It follows, then, that the reference of a quasi-rigid term in a given world is not determined as the single individual it denotes in that world. This is clearly a negative result for Kripke's account, as it directly contradicts the Rule of Rigidity (Kripke, 1980: 10). This can be fixed by adding enough stipulations, so that we get a single counterpart in each world (see Torza, 2012). But it would still be the case that a proper name may "be quasi-rigid relative to one possible world and not relative to another" [Stalnaker, 1997:553]. It would be incorrect to say, with Kripke (1980), that ordinary proper names are rigid designators. Rather, rigidity would appear to be a relation that proper names may have relative to certain contexts (or worlds).

Furthermore, given that, according to the Millian view famously defended by Kripke (1980), the semantic value of a proper name is fully determined by its reference, the semantic theory of proper names is also affected. Given that reference is determined by counterpart relations, according to quasi-rigidity, the semantic value of a proper name is determined by the relevant counterpart relations. Thus, instead of keeping the semantic referentialism common to Millian views, quasi-rigidity has on offer a form of descriptivism based on descriptions of counterpart relations. As a consequence, we would no longer be able to distinguish between proper names and definite descriptions on the basis of their rigidity or 
lack thereof, as Kripke (1980) does. Quasi-rigidity is so flexible that even 'the teacher of Alexander the Great' will be quasi-rigid relative to a world, it need only denote a counterpart of Aristotle in that world.

Finally, the ontological expense of quasi-rigidity is perhaps its most substantial cost. As I said already, quasi-rigidity relies on counterpart relations, which are nothing more than natural relations of comparative similarity among distinct objects. However, for there to be such natural relations of comparative similarity the relata must exist in the same spatiotemporal manner as the said relations. This is where the ontological cost kicks in. As Lewis (1986) famously argues, the only way to guarantee that we will have all the need counterpart relations is for there to exist a plurality of possible worlds and individuals, all of them equally real, concrete, mind-independent and spatiotemporally located as we ourselves are in our own world. Without concrete possibilia there are no counterparts to be the relata for the needed relations of comparative similarity, without such relations no counterpart relations either and, hence, no way to determine the reference (in any merely possible world) of any quasi-rigid term. Briefly put, without endorsing modal realism and its plurality of worlds there is no quasi-rigidity.

Some may think that these are not knock-down reasons to reject quasi-rigidity. After all, there is nothing intrinsically wrong — or so it seems, see García-Ramírez and Shatz, 2011 - in endorsing a descriptivist account of reference and semantics for proper names. Yet, endorsing modal realism in order to account for speaker intuitions about contingent identity statements seems unhinged. If anything, quasi-rigidity should be kept merely as our last resort.

\subsection{Restricted Rigidity}

Let me now consider the last alternative available in the literature. To achieve the needed referential flexibility exhibited by names in statements (4) to (8), Gallois (1986) and (1998) proposes that we relativize all predicates/properties to a world. Thus, the property of being identical to $a$, for any $a$, is itself relativized to a world. Given that identity is part of the very definition of rigidity, we need to modify the original version and offer a new definition of a rigid designator. Instead of Kripke's (1980) notion of a rigid designator, we have the rigid designation condition (RDC):

$R D C: d$ is a rigid designator of $x$ in world @ if and only if the following obtains: if it designates object $y$ in W then there is something $z$ that is identical to $x$ in @ and identical to $y$ in W. [See Gallois, 1993:153] 
Gallois makes it possible for an object to be identical with another object at a distinct specific possible world while at the same time having different identity relations with respect to other different worlds. Whatever $a$ is identical to in the actual world need not be identical to whatever it is identical to in world $W$. Yet, somehow we can still guarantee identity throughout all the relevant worlds since there is an object $\%$, which happens to be identical to whatever the name designates anywhere, namely $a$.

Gallois's proposal has a few problematic consequences that explain why it "has not found many supporters". [Schwartz, 2013:492] First, the notion of identity it presupposes differs so much from what is typically understood as identity that it is hard to see in what sense it is that notion. It is generally assumed that identity is both symmetric and transitive, such that if $x$ is identical to $y$, then $y$ is also identical to $x$; and if $y$ also happens to be identical to $\%$ then $x$ is also identical to $\%$. This is not true of Gallois's notion of identity. On his view identity is not transitive as $a$ may be identical to $b$ in the actual world and to $c$ in possible world $W$ even without $b$ and $c$ being identical at all. It follows that Leibniz's principle of indiscernibility of identicals does not hold among identical objects and that, paradoxically, nonidentical objects (e.g., $b$ and $c$ ) may nonetheless be part of an identity relation.

Second, Gallois's proposal gets rid off intrinsic properties, all of them. On Gallois's view, objects have all of their properties in virtue of how they relate to worlds (see Lewis, 1986:198-202). As a consequence of this, it turns out that there are no intrinsic properties, not even those an object may have in virtue of its form, as all properties (modal or not) are relations that objects hold with respect to some or other world.

Third, and last, Gallois's proposal requires that world indexes pile up. Nonmodal properties are, for some reason, world relative. Modal properties are doubly so. Aristotle has the non-modal property of being 5 feet tall at the actual world and the modal property of being 7 feet tall at the actual world, at world $W$.

It is rather hard to see how it is that Gallois's proposal accounts for the intuitions of contingency associated with certain identity statements. On this view, being contingently identical is not a property but a relation that certain objects may hold relative to certain worlds at a given world. Even if this notion is somehow clarified in a way that does not turn it into a mere cumbersome description of a necessary statement of identity, Gallois's account seems to have great ontological cost: we no longer have the traditional, simple, symmetric and transitive relation of identity; the resulting notion of identity seems paradoxical; there are no intrinsic properties, only relations to possible worlds; and there are no non-modal 
properties strictly speaking. It would be much easier, and a more satisfactory account, to simply accept that certain identity statements are contingently true and, hence, that in such cases the proper names used are not rigid designators.

\section{Rigidity And Contingency}

Intuitions $\mathrm{E}_{3}$ and $\mathrm{E}_{4}$ pose a difficult theoretical challenge. They seem to point in opposite directions. On the one hand, $\mathrm{E}_{3}$ points towards rigidity and, indirectly, towards the necessity of identity. On the other hand, $\mathrm{E}_{4}$ directly points towards the contingency of identity. It is difficult to see how to account for both. In this section I want to merely gesture toward an alternative view of proper names that can account for both $\mathrm{E}_{3}$ and $\mathrm{E}_{4}$.

The thesis that true identity statements involving proper names are necessary truths is a consequence of the assumption that proper names are rigid designators. A further assumption is needed to guarantee that no true identity statement involving proper names may ever be contingently true. For this latter result to be obtained it must be that the rigidity of proper names is a necessary, perhaps essential feature of them. It must be impossible to use a proper name competently to refer to an object and fail to do so rigidly. In other words, rigidity must be a semantic, obligatory feature of proper names.

This latter assumption is not, however, an obvious one. Kripke (1980) himself does not make any claim as to whether rigidity is a semantic or, alternatively, a pragmatic feature of proper names. Traditionally philosophers have simply assumed the former without further argument. Yet if it is the latter, if rigidity is a context-dependent, pragmatic feature of referential uses of proper names, then the possibility is open for non-rigid referential uses of proper names. If such were the case, we could account for both $\mathrm{E}_{3}$ and $\mathrm{E}_{4}$ as competent intuitions associated with distinct referential uses of proper names. $\mathrm{E}_{3}$ accompanies contexts where names are used, either by assumption or by stipulation, rigidly. $\mathrm{E}_{4}$ accompanies contexts where names are used, either by assumption or by stipulation, non-rigidly.

Rejecting the widely held assumption that rigidity is a semantic, obligatory feature of all referential uses of ordinary proper names gives us a way to account for both conflicting intuitions in a substantive way. It is not that they are inconsistent intuitions, but rather that they are context-sensitive. Proper names are sometimes, perhaps most of the time, rigidly used. When they are not, they may give place to the intuition of contingency. Let me conclude this brief gesture towards a pragmatic account of rigidity by illustrating how competent speakers may benefit 
from contextual features to make a referential, yet non-rigid, use of an ordinary proper name.

Consider again the historical case presented by Lewis' (1986) concerning the Great Western Railway.

The Great Western Railway ought to have absorbed two other railways early on: the Bristol and Gloucester, and the Birmingham and Gloucester. But it tried to drive too hard a bargain. In 1845 the line from Bristol to Gloucester to Birmingham fell into rival hands. Therefore, after the grouping of railways in 1923, the postgrouping Great Western lacked a part that it might have had. What we know as the Great Western, without the missing line, was the whole of the Great Western; not, as it so easily might have been, a part of a still Greater Western. [Lewis, 1986:248]

Take sentence (9), it contains the name 'Great Western Railway' that directly refers to the actual railway running from London to the southwest and west of England. Intuitively, an ordinary modal claim such as (9) is true.

(9) The Great Western Railway could have been bigger than it currently is.

In fact, it seems intuitive (following Kripke) that 'Great Western Railway' is being rigidly used in (9) as the truth of the proposition expressed by it depends on what goes on with the Great Western Railway across possible worlds.

Now let us stipulate that 'Greater Western Railway' refers to the railway that would have existed had negotiations gone differently, with the Great Western Railway successfully absorbing the other two lines. With this stipulation as part of the context of use of 'Great Western Railway' and 'Greater Western Railway', we can infer (10), which seems intuitively true. Yet (10), even though it is a true identity statement, cannot be considered to be necessary, since in this same context (11) follows from (9) and the said stipulation. And (11) seems just as intuitively true as (10).

(10)The Great Western Railway is not the Greater Western Railway.

(11) The Great Western Railway could have been the Greater Western Railway.

The truth of the pair of statements (10)-(11) shows more clearly how ordinary names may be used in referential yet non-rigid ways. Exactly how this happens and what role the relevant stipulation plays is yet to be determined. The example shows, however, that the rigidity of ordinary proper names may vary from context to context, as 'Great Western Railway' appears to be rigid in (9) and non-rigid in the pair (10)-(11). A detailed account of how context may change 
the rigidity / non-rigidity of referential uses of proper names is certainly needed. Fully achieving such a goal goes beyond the limits of the present work. Suffice it to say that a presupposition-based account, according to which rigidity is a conventional yet eliminable presupposition that typically accompanies referential uses of proper names may do the explanatory work. ${ }^{5}$

\section{Some Philosophical Consequences}

The received view, according to which proper names are essentially (unavoidably) rigid, is related to multiple discussions in philosophy of language, philosophy of mind, epistemology and metaphysics among many others. It is natural to wonder about the fate of at least some of these debates if we were to adopt the view that rigidity is a context-dependent feature of names. Let me briefly consider some of them.

A term is directly referential if it does not pick out its denotation by means of mediating descriptive information. If the context-dependent view suggested is correct, there is no substantial relation between direct reference and rigidity. The former depends on the semantics for names, the latter on contextual features of their use. Thus, there may be directly referential terms that are used non-rigidly in certain contexts, for example, 'Lumpl', 'Goliath', 'Great Western Railway'.

Definite Descriptions are said to be a distinct kind of expression modally differing from proper names. The received view claims this is a difference of rigidity and that, as such, it is a semantic difference. If rigidity turns out to be a contextual feature there may still be a substantial difference between ordinary proper names and definite descriptions, but it seems it would be a difference in use and not a semantic one.

Last, but not least, consider contingent identity statements. Unlike the received view, the contextual view suggested in section 4 shows how identity statements involving ordinary proper names may be contingently true. The consequences of this result are plenty. It clears the path in multiple areas of philosophy - i.e., personal identity, persistence through time, social metaphysics, etc. — where a coherent and metaphysically simple notion of contingently true identity statements is needed (see Lewis, 1983).

One salient case in point is the metaphysics of mind. Kripke (1980) famously argued that, since identity statements involving proper names can only be necessarily

\footnotetext{
${ }^{5}$ See García-Ramírez (forthcoming) for a detailed account.
} 
true, then the mind-brain identity thesis must be false. This now seems mistaken, identity statements involving proper names may also be contingently true. So the mind-brain identity thesis may be rescued. A closer look at Kripke (1980) suggests that he benefits from using proper names in contexts that suggest a non-rigid interpretation.

Let ' $\mathrm{A}$ ' name a particular pain sensation, and let ' $\mathrm{B}$ ' name the corresponding brain state. Prima facie, it would seem that it is at least logically possible that $B$ should have existed (Jones's brain could have been in exactly that state at the time in question) without Jones feeling any pain at all, and thus without the presence of $A$. [Kripke, 1980: 146]

Kripke fixes the context in two ways. On the one hand, he introduces a modal distinction between two objects, A and B. He thereby creates a context that selects the relevant features that make true what he says. On the other hand, he introduces new names by associating them each with a different object. The resulting context is pretty obviously inconsistent with the claim that one and the same object is being referred to across counterfactual scenarios. Naturally, 'A' and 'B will not be rigidly interpreted. No wonder why the truth of " $\mathrm{A}=\mathrm{B}$ " seems contingent.

$$
\begin{array}{r}
\text { Eduardo Garcia Ramírez, } \\
\text { Instituto de Investigaciones Filosóficas - UNAM } \\
\text { edu@filosoficas.unam.mx }
\end{array}
$$

\section{BiBLIOGRAFÍA}

BALDwin, T. (1984): "Lowe on modalities de re." Mind, 93, 370, pp. 252-255.

Gallois, A. (1986): "Rigid designation and the contingency of identity", Mind, 95, 377, pp. $57-76$.

Gallois, A. (1998): Ocassions of Identity. Oxford: Clarendon Press.

GarCía-RAmíreZ, E., forthcoming. "A pragmatic account of rigidity”. (ms), IIFs-UNAM.

García-Ramírez, E. and ShatZ, M. (2011): "On problems with descriptivism: Psychological assumptions and empirical evidence." Mind \& Language, 26 (1), pp. 53-77.

GibBARD, A. (1975): “Contingent Identity”, Journal of Philosophical Logic, 4, pp. 187-221. Johnston, M. (1992): “Constitution is not identity", Mind, 101, 401, pp. 89-105.

KADMON, N. (2001): Formal Pragmatics. Blackwell Publishing.

Kaplan, D. (1989): "Demonstratives," in J. Almog, H. Wettstein, and J. Perry (eds.), Themes From Kaplan. Oxford: Oxford University Press, pp. 481-563.

KARmo, T. (1983): “Contingent Non-Identity”, Australasian Journal of Philosophy, 61, 2, pp. 185-7. 
KRIPKE, S. (1971): "Identity and necessity". In M.K. Munitz (ed.), 1971: Identity and Individuation. New York University Press, pp. 135-164.

KRIPKE, S. (1980): Naming and Necessity. Cambridge, MA: Harvard University Press.

LEWIS, D. (1968): "Counterpart theory and quantified modal logic", The Journal of Philosophy, 65, 5, pp. 113-126.

LEWIS, D. (1983): "Counterparts of Persons and their Bodies", in D. Lewis, 1983. Philosophical Papers Vol. 1. Oxford: Oxford University Press.

LEWIS, D. (1986): On the Plurality of Worlds. Oxford: Blackwell.

LowE, E. (1982): “On the alleged necessity of true identity statements.", Mind, 91, pp. 579-84.

Myro, G. (1986a): “Identity and time”. In R. Grandy and R. Warner (eds.), Philosophical Grounds of Rationality: Intentions, Categories, and Ends. Oxford: Clarendon Press, pp. 383-409.

Myro, G. (1986b): “Time and essence”, Midwest Studies in Philosophy, 11, 1, pp. 331-341.

NoOnAN, H.W. (1991): "Indeterminate identity, contingent identity and Abelardian predicates", The Philosophical Quarterly, 41, pp. 183-193.

Noonan, H.W. (1993): “Constitution is identity”, Mind, 102, pp. 133-146.

Perry, J. (1972): “Can the self divide?”. Journal of Philosophy, 69, pp. 463-488.

SALMON, N. (1982): Reference and Essence. Oxford: Blackwell.

SAlmon, N. (2003): "Naming, Necessity and Beyond". Mind, 112, pp. 475-492.

SCHWARTZ, W. (2013): “Contingent Identity”, Philosophy Compass, 8, 5, pp. 486-495.

SoAmes, S. (2002): Beyond Rigidity. New York: Oxford University Press.

Stalnaker, R. (1987): "Counterparts and Identity", In R. Stalnaker, 2003. Ways the World Might Be. Oxford: Oxford University Press.

Stalnaker, R. (1997): "Reference and Necessity", in in B. Hale and C. Wright (eds.), 1997. A Companion to the Philosophy of Language. Oxford: Blackwell.

Stalnaker, R. (2003): Ways a World Might Be. Oxford: Oxford University Press.

Stanley, J. (1997): "Names and rigid designation" in B. Hale and C. Wright (eds.), 1997. A Companion to the Philosophy or Language. Oxford: Blackwell.

TorzA, A. (2012): “Identity' without identity”. Mind, 121, 481, pp. 67-95.

WALters, L. (2017): “Are the statue and the clay mutual parts?". Nô̂s, doi: 10.1111/nous 12204, pp. 1-28.

YABLO, S. (1987): "Identity, essence and indiscernibility." Journal of Philosophy, 84, 6, pp. 293-314. 